\title{
Assessment of RV Systolic Function by Two-Dimensional Speckle Tracking Echocardiography in Patients with Preeclampsia before and after Labor \\ Mohamed H. Hassan ${ }^{(1)}$, Abd EL Hamid I. Abd EL Hamid ${ }^{(1)}$, Ahmed O. Abdel-Motaal ${ }^{(2)}$, Hazem A. Mahmoud ${ }^{(1)}$
}

(1) Department of Cardiology and (2) Department of Obstetrics and Gynecology, Faculty of Medicine, Al-Azhar University, Cairo.

Corresponding author: Hazem A. Mahmoud, Mobile: (+20) 01061056031, E-mail: ramyhazem94@ gmail.com

\begin{abstract}
Background: preeclampsia (PE) is one of the most common causes of maternal mortality and morbidity worldwide. Although cardiovascular (CV) risk is increased after PE, a direct causative relationship has not yet been determined. Aim of the Work: to evaluate and detect subclinical RV dysfunction by 2D speckle tracking echocardiography in preeclamptic patients before and after labor.

Patients and Methods: 60 pregnant women were selected for this sectional comparative study which was conducted at Cardiology Department, Faculty of Medicine, Al-Azhar University during the period from October 2018 to June 2019.

Results: comparison between before labor and 6 weeks after labor of the right ventricle of the preeclamptic patients showed that tricuspid annular plane systolic excursion (TAPSE) was $22.33 \pm 3.08$ and $26.48 \pm 2.20$, respectively with change of $4.15(18.6 \%)$, with a statistically highly significant difference $(\mathrm{p}<0.001)$, end-systolic pulmonary arterial pressure (ESPAP) was $14.65 \pm 1.63 \mathrm{mmHg}$ and $8.35 \pm 1.76 \mathrm{mmHg}$, respectively with change of $-6.3(43 \%)$, it showed a statistically highly significant difference $(\mathrm{p}<0.001)$, fractional area change (FAC) was $50.55 \pm 2.25$ and $53.40 \pm 1.66$, respectively with change of $2.85(5.6 \%)$, it showed a statistically highly significant difference $(\mathrm{p}<0.001)$, right ventricular index of myocardial performance (RIMP) was $41.45 \pm 2.11$ and $33.28 \pm 2.34$, respectively with change of $-8.17(19.7 \%)$.

Conclusions: two-dimensional speckle echocardiography proved to be acceptable, and applicable for assessing rightsided heart function in patients with preeclampsia. Using this image modality demonstrated significant differences in right ventricular measurements to overcome further morbidity and mortality of those patients.
\end{abstract}

Keywords: RV systolic function, two-dimensional speckle tracking echocardiography, preeclampsia labor.

\section{INTRODUCTION}

Preeclampsia is a pregnancy-specific disorder that complicates $2 \%-8 \%$ of pregnancies worldwide ${ }^{(\mathbf{1})}$. Traditionally the condition is diagnosed in the case of de novo development of hypertension (> 140/90 $\mathrm{mmHg}$ ) and proteinuria during the second half of pregnancy (>20 weeks of gestation) ${ }^{(2)}$.

Preeclampsia is often classified based on the gestational age at onset of the disease; early-onset preeclampsia is defined as the onset of preeclampsia before 34 weeks of gestation and late-onset preeclampsia, as the onset of preeclampsia at or after 34 weeks of gestation ${ }^{(3)}$.

Preeclampsia is associated with an increased risk of developing cardiovascular disease in later life. The cardiovascular disorders and preeclampsia share various pathophysiologic mechanisms. Preeclampsia is related to progressive cardiovascular changes, including hypertension, vasomotor dysfunction, endothelial damage, inflammation, and metabolic disturbance ${ }^{(4)}$.

However, the underlying pathophysiologic mechanisms of preeclampsia that could produce increased risk of long-term cardiovascular disorder are not defined ${ }^{(\mathbf{5})}$.

Although a direct correlation was been determined yet, a higher risk of essential hypertension was reported in early onset preeclampsia. Therefore, the analysis of predicting factors for essential hypertension in preeclampsia might be meaningful ${ }^{(6)}$.

Transthoracic echocardiography (TTE) is a common noninvasive diagnostic tool that can be safely used during pregnancy to evaluate cardiac structure and function with two-dimensional (2D) scan, Mmode, and Doppler. Particularly, tissue Doppler imaging (TDI) is a new method of non-invasive myocardial strain measurement, which has potential advantages in evaluating additional risk factors for cardiac performance status ${ }^{(7)}$. Proper use of TTE in preeclampsia can be useful to determine the severity and to predict the prognosis ${ }^{(4)}$.

Echocardiography is a noninvasive, widely available, fast, and fairly accurate technique for the assessment of right ventricular (RV) function, despite several limitations related to RV geometry and shape and the need for RV-focused views that will be discussed in detail later, and it is considered a good first-line tool for the evaluation of the right heart. The recent application of newer myocardial deformation techniques to the right ventricle has allowed the earlier detection of subtle RV dysfunction, upgrading the role of echocardiography in everyday clinical practice. Myocardial deformation can be studied using different ultrasound techniques, but the most used are twodimensional (2D) and three-dimensional (3D) speckletracking echocardiographic (STE) strain. STE imaging 
provides frame-by-frame tracking of natural acoustic markers, is angle independent, is not influenced by translational movement due to respiration or tethering by the adjacent myocardium, and is less sensitive to signal noise ${ }^{(8)}$. Previous echocardiographic studies have reported conflicting results, mainly because they have used different echocardiographic techniques and assessed load-dependent indices in different patient groups. Moreover, most of the studies have focused on functional and structural alterations occurring in the left side of the heart. There is a lack of published data on the myocardial structure and function of the right side of the heart in $\mathrm{PE}^{(9)}$.

\section{AIM OF THE WORK}

The purpose of this study was to evaluate and detect subclinical RV dysfunction by 2D speckle tracking echocardiography in preeclamptic patients before and after labor.

\section{SUBJECTS AND METHODS}

This cross-sectional comparative study involved 60 female patients collected from the Obstetrics and Gynecology Clinic of El-Hussain University Hospital and were screened for the study enrollment prospectively. The study was performed at Cardiology Department, Faculty of Medicine, AlAzhar University at the period from October 2018 to June 2019.

The patients were divided into two groups:

Group (I): 40 pregnant women who diagnosed to have preeclampsia.

Group (II): 20 women with normal pregnancy serve as control subjects.

\section{Inclusion criteria:}

The current study included patients with ages more than or equal to 18 years old, pregnant women at $\geq 20$ weeks gestation and patients diagnosed with preeclampsia who did not have chronic or autoimmune diseases and able to understand instructions and provide informed consent.

\section{Exclusion criteria:}

Known hypertensive, pregnancy $<20$ weeks' gestation, diabetic patients, detection of relevant regional wall motion abnormalities (RWMA) at rest by 2D conventional echocardiography, moderate and severe valvular heart disease, patients with cardiomyopathy whatever its cause, patients with any type of pulmonary hypertension, patients with underlying RV dysfunction, patients with atrial fibrillation (AF), poor image quality, significant comorbidities, patients that declined consent, uncooperative patients, patients with bad compliance and inability to give informed consent were excluded from the study.

\section{II- Technical Design:}

All patients were subjected to the following: personal history: name, age, sex, residence and occupation, past history: history of previous medical illness, history of previous drug intake, history of menstrual cycle, history of parity, present history: history of pregnancy, assessment of last menstrual period (LMP) to determine GA and EDD, history of confirmation of pregnancy, cardiac or lung comorbidities, full general examination including cardiac, chest, abdominal and obstetrical examination: blood pressure and pulse rate measurement, both upper and lower limbs for edema, head and neck examination, chest and abdominal examination, full cardiac examination, urine analysis to detect significant proteinuria, obstetric ultrasonography to confirm pregnancy, fetal viability and GA and resting surface 12 leads ECG were done for all patient, echocardiography

\section{Echocardiographic examination:}

All patients were examined at rest in the left lateral decubitus position to obtain adequate images in different standard views.

Chamber quantification was performed in accordance with the recommendations of the American Society of Echocardiography and Assessment of the Right Heart in Adults (10,11) respectively.

\section{Two- dimensional echocardiography (STE)}

Two- dimensional (2D) strain represents myocardial deformation from a 2D point of view. Negative strain represents shortening, while positive strain indicates thickening of a given myocardial segment.

\section{Ethical approval and written informed consent:} An approval of the study was obtained from Al- Azhar University academic and ethical committee. Every patient signed an informed written consent for acceptance of the operation.

\section{Statistical analysis:}

Recorded data were analyzed using the statistical package for social sciences, version 20.0 (SPSS Inc., Chicago, Illinois, USA). Quantitative data were expressed as mean \pm standard deviation (SD). Qualitative data were expressed as frequency and percentage.

\section{The following tests were done:}

- Independent-samples t-test of significance was used when comparing between two means.

- Chi-square $\left(\mathrm{x}^{2}\right)$ test of significance was used in order to compare proportions between two qualitative parameters.

- The confidence interval was set to $95 \%$ and the margin of error accepted was set to 5\%. The p-value was considered significant as the following:

- Probability (P-value)

- P-value <0.05 was considered significant.

- P-value <0.001 was considered as highly significant.

- P-value >0.05 was considered insignificant 
RESULTS

Table (1): Demographic data of the patients and controls

\begin{tabular}{|l|c|c|c|}
\hline Demographic data & $\begin{array}{c}\text { Patients } \\
(\boldsymbol{n = 4 0 )}\end{array}$ & $\begin{array}{c}\text { Control } \\
(\boldsymbol{n}=\mathbf{2 0})\end{array}$ & p-value \\
\hline $\begin{array}{l}\text { Age (years) } \\
\text { Mean } \pm \text { SD }\end{array}$ & $\begin{array}{c}28.65 \pm 5.42 \\
19-40\end{array}$ & $\begin{array}{c}27.45 \pm 6.36 \\
18-40\end{array}$ & 0.449 \\
Range & $2.08 \pm 1.53$ & $1.75 \pm 1.52$ & 0.439 \\
\hline PAR & $0-5$ & $0-4$ & 0.531 \\
Mean \pm SD & $3.13 \pm 1.62$ & $2.85 \pm 1.53$ & \\
Range & $1-6$ & $1-5$ & $<0.001^{* *}$ \\
\hline GRAV & $32.50 \pm 2.39$ & $37.70 \pm 1.13$ & \\
Mean \pm SD & $28-37$ & $36-40$ & \\
Range & & \\
\hline GA (weeks) & & \\
Mean \pm SD & &
\end{tabular}

p-value $>0.05 \mathrm{NS} ; * *$ p-value $<0.001 \mathrm{HS}$

This table shows statistically significant difference between patients and control according to GA.

Table (2): Comparison between patients and control groups according to clinical data

\begin{tabular}{|l|c|c|c|}
\hline \multicolumn{1}{|c|}{ Clinical data } & $\begin{array}{c}\text { Patients } \\
(\boldsymbol{n}=\mathbf{4 0})\end{array}$ & $\begin{array}{c}\text { Control } \\
(\boldsymbol{n}=\mathbf{2 0})\end{array}$ & p-value \\
\hline BMI [wt/(ht)^2] & $28.55 \pm 2.11$ & $27.25 \pm 1.59$ & $0.018^{*}$ \\
Mean \pm SD & $25-33$ & $24-29$ & \\
Range & & & $<0.001^{* *}$ \\
\hline Systolic (mmHg) & $163.13 \pm 16.28$ & $108.5 \pm 8.75$ & $100-130$ \\
Mean \pm SD & $145-200$ & & \\
Range & $97.38 \pm 5.77$ & $73.25 \pm 4.38$ & $<0.001^{* *}$ \\
\hline Diastolic (mmHg) & $90-110$ & $70-80$ & \\
Mean $\pm S D$ & & & \\
Range & &
\end{tabular}

$*$ p-value $<0.05 \mathrm{~S}$; **p-value $<0.001 \mathrm{HS}$

This table shows statistically significant difference between patients and control according to blood pressure.

Table (3): PIU distribution of the patients group.

\begin{tabular}{|c|c|}
\hline PIU & Total \\
\hline+ & $12(30 \%)$ \\
\hline++ & $11(27.5 \%)$ \\
\hline+++ & $17(42.5 \%)$ \\
\hline Total & $40(100 \%)$ \\
\hline
\end{tabular}

Table (4): Comparison between patients and control according to left ventricle at echo 2D.

\begin{tabular}{|l|c|c|c|}
\hline \multicolumn{1}{|c|}{$\begin{array}{c}\text { Left ventricle } \\
\text { at Echo 2D }\end{array}$} & $\begin{array}{c}\text { Patients } \\
(\boldsymbol{n}=\mathbf{4 0})\end{array}$ & $\begin{array}{c}\text { Control } \\
(\boldsymbol{n}=\mathbf{2 0})\end{array}$ & p-value \\
\hline LVEDD (mm) & $49.00 \pm 1.50$ & $48.30 \pm 2.25$ & 0.157 \\
Mean \pm SD & $47-53$ & $45-52$ & \\
Range & $29.18 \pm 1.97$ & $28.55 \pm 2.26$ & 0.421 \\
\hline LVESD (mm) & $26-33$ & $25-31$ & \\
Mean \pm SD & $40.43 \pm 3.08$ & $41.75 \pm 2.22$ & 0.671 \\
Range & $33-46$ & $38-45$ & \\
\hline FS\% & & & \\
Mean \pm SD & $69.58 \pm 2.19$ & $68.90 \pm 1.94$ & 0.099 \\
Range & $65-74$ & $66-70$ & \\
\hline EF\% & & & \\
Mean \pm SD & & & \\
Range &
\end{tabular}

$p$-value >0.05 NS; This table shows no statistically significant difference between patients and control according to left ventricle at echo $2 \mathrm{D}$. 
Table (5): Comparison between patients and control according to right ventricle at Echo 2D.

\begin{tabular}{|l|c|c|c|}
\hline \multicolumn{1}{|c|}{$\begin{array}{c}\text { Right ventricle } \\
\text { at Echo 2D }\end{array}$} & $\begin{array}{c}\text { Patients } \\
(\boldsymbol{n}=\mathbf{4 0})\end{array}$ & $\begin{array}{c}\text { Control } \\
(\boldsymbol{n}=\mathbf{2 0})\end{array}$ & p-value \\
\hline $\begin{array}{l}\text { TAPSE (mm) } \\
\text { Mean } \pm \text { SD }\end{array}$ & $\begin{array}{c}2.33 \pm 3.08 \\
17-26\end{array}$ & $\begin{array}{c}28.35 \pm 0.93 \\
27-30\end{array}$ & $<0.001^{* *}$ \\
Range & $\begin{array}{c}10.20 \pm 0.95 \\
8-12\end{array}$ & $<0.001^{* *}$ \\
\hline $\begin{array}{l}\text { ESPAP (mmHg) } \\
\text { Mean } \pm \text { SD } \\
\text { Range }\end{array}$ & $11-18$ & & \\
\hline FAC\% & $47.50 \pm 4.75$ & $52.55 \pm 2.25$ & $0.026^{*}$ \\
Mean \pm SD & $44-53$ & $47-55$ & \\
Range & & & \\
\hline RIMP & $41.45 \pm 2.11$ & $31.80 \pm 0.83$ & $<0.001^{* *}$ \\
Mean \pm SD & $38-45$ & $31-33$ & \\
Range & $16.20 \pm 2.13$ & $29.90 \pm 2.64$ & $0.044^{*}$ \\
\hline TDI (S) & $13-21$ & $20-31$ & \\
Mean \pm SD & & \\
Range &
\end{tabular}

$* p$-value $<0.05 \mathrm{~S}$; **p-value $<0.001 \mathrm{HS}$; This table shows statistically significant difference between patients and control according to right ventricle at echo $2 \mathrm{D}$.

Table (6): Comparison between patients and control according to G LS (2D speckle).

\begin{tabular}{|c|c|c|l|}
\hline $\begin{array}{c}\text { GLS } \\
\text { (2D speckle) }\end{array}$ & $\begin{array}{c}\text { Patients } \\
(\boldsymbol{n}=\mathbf{4 0})\end{array}$ & $\begin{array}{c}\text { Control } \\
(\boldsymbol{n}=\mathbf{2 0})\end{array}$ & p-value \\
\hline Mean \pm SD & $-18.90 \pm 2.01$ & $-22.85 \pm 0.88$ & \multirow{2}{*}{$001^{* *}$} \\
\hline Range & -22 to -16 & -24 to -21 & \\
\hline
\end{tabular}

**p-value $<0.001 \mathrm{HS}$, This table shows highly statistically significant difference between patients and control according to GLS (2D speckle).

Table (7): Echo 2D at follow up 6 weeks descriptive data of patients group.

\begin{tabular}{|l|c|c|}
\hline \multicolumn{1}{|c|}{ Follow UP 6 weeks Echo 2D } & Mean \pm SD & Range \\
\hline Left ventricle & & $47-53$ \\
\hline LVEDD $(\mathbf{m m})$ & $50.38 \pm 1.15$ & $26-33$ \\
\hline LVESD $(\mathbf{m m})$ & $30.65 \pm 1.58$ & $34-46$ \\
\hline FS\% & $39.05 \pm 2.67$ & $64-71$ \\
\hline EF\% & $66.98 \pm 1.49$ & $21-29$ \\
\hline Right ventricle & & $5-13$ \\
\hline TAPSE & $26.48 \pm 2.20$ & $50-58$ \\
\hline ESPAP & $8.35 \pm 1.76$ & $30-38$ \\
\hline FAC & $53.40 \pm 1.66$ & $16-23$ \\
\hline RIMP & $33.28 \pm 2.34$ & $-20--25$ \\
\hline TDI (S) & $19.40 \pm 1.58$ & $-22.83 \pm 1.36$ \\
\hline GLS (2D speckle) & & \\
\hline
\end{tabular}

Table (8): Comparison between before labor and follow up after 6 weeks according to left ventricle of the patients group

\begin{tabular}{|l|l|c|c|c|c|}
\hline $\begin{array}{c}\text { Echo 2D } \\
\text { Left ventricle }\end{array}$ & Before Labor & $\begin{array}{c}\text { Follow up } \\
\text { after 6 weeks }\end{array}$ & Iean diff. & Change\% & p-value \\
\hline LVEDD $(\mathrm{mm})$ & $49.00 \pm 1.50$ & $50.38 \pm 1.15$ & 1.38 & 2.80 & $<0.001^{* *}$ \\
\hline LVESD $(\mathrm{mm})$ & $29.18 \pm 1.97$ & $30.65 \pm 1.58$ & 1.47 & 5.00 & $<0.001^{* *}$ \\
\hline FS\% & $40.43 \pm 3.08$ & $39.05 \pm 2.67$ & -1.38 & 3.40 & $0.002^{*}$ \\
\hline EF\% & $69.58 \pm 1.89$ & $66.98 \pm 1.49$ & -2.60 & 3.70 & $<0.001^{* *}$ \\
\hline
\end{tabular}

$*$ p-value $<0.05 \mathrm{~S} ; * * p$-value $<0.001 \mathrm{HS}$; This table shows statistically significant difference between before labor and follow up after 6 weeks according to left ventricle of patients group. 
Table (9): Comparison between before labor and follow up after 6 weeks according to right ventricle of the patients group

\begin{tabular}{|l|l|l|l|c|c|}
\hline $\begin{array}{c}\text { Echo 2D } \\
\text { RV }\end{array}$ & Before Labor & $\begin{array}{c}\text { Follow up } \\
\text { after 6 weeks }\end{array}$ & $\begin{array}{l}\text { Mean } \\
\text { diff. }\end{array}$ & Change\% & p-value \\
\hline TAPSE & $22.33 \pm 3.08$ & $26.48 \pm 2.20$ & 4.15 & 18.60 & $<0.001^{* *}$ \\
\hline ESPAP & $14.65 \pm 1.63$ & $8.35 \pm 1.76$ & -6.30 & 43.00 & $<0.001^{* *}$ \\
\hline FAC & $50.55 \pm 2.25$ & $53.40 \pm 1.66$ & 2.85 & 5.60 & $<0.001^{* *}$ \\
\hline RIMP & $41.45 \pm 2.11$ & $33.28 \pm 2.34$ & -8.17 & 19.70 & $<0.001^{* *}$ \\
\hline TDI (S $)$ & $16.20 \pm 2.13$ & $19.40 \pm 1.58$ & 3.20 & 19.80 & $<0.001^{* *}$ \\
\hline
\end{tabular}

**p-value $<0.001 \mathrm{HS}$

This table shows statistically significant difference between before labor and follow up after 6 weeks according to right ventricle of patients group.

Table (10): Comparison between before labor and follow up after 6 weeks according to GLS (2D speckle) of patients group.

\begin{tabular}{|l|l|l|l|l|l|}
\hline Echo 2D & Before labor & $\begin{array}{c}\text { Follow up } \\
\text { after 6 weeks }\end{array}$ & $\begin{array}{l}\text { Mean } \\
\text { diff. }\end{array}$ & Change \% & p-value \\
\hline $\begin{array}{l}\text { GLS } \\
(2 \mathrm{D} \text { speckle) }\end{array}$ & $-18.90 \pm 2.01$ & $-22.83 \pm 1.36$ & -3.93 & 20.80 & $<0.001 * *$ \\
\hline
\end{tabular}

$t$-Paired Sample t-test; **p-value <0.001 HS

This table shows highly statistically significant difference between before labor and follow up after 6 weeks according to GLS (2D speckle) of patients group.

Table (11): Correlation between GLS (2D speckle) with TAPSE (mm) in patients group, using Pearson Correlation Coefficient.

\begin{tabular}{|c|l|l|c|}
\hline \multicolumn{2}{|c|}{} & \multicolumn{2}{|c|}{ GLS (2D speckle) } \\
\cline { 3 - 4 } \multicolumn{2}{|c|}{} & Before Labor & Follow UP After 6 weeks \\
\hline \multirow{2}{*}{ TAPSE $(\mathrm{mm})$} & $\mathrm{R}$ & 0.919 & 0.623 \\
\cline { 2 - 4 } & $\mathrm{p}$-value & $<0.001^{* *}$ & $<0.001^{* *}$ \\
\hline
\end{tabular}

Statistically significant correlation between GLS (2D speckle) with TAPSI (mm) in patients group, using Pearson correlation coefficient.

\section{DISCUSSION}

Preeclampsia (PE) is a life-threatening condition in pregnancy and a major cause of maternal and neonatal morbidity and mortality. It affects $3-8 \%$ of pregnancies that develop serious complications such as eclampsia, hemolysis, elevated liver enzyme levels, thrombocytopenia, and pulmonary edema. These end organ damages usually disappear 12 weeks after delivery ${ }^{(\mathbf{1 2})}$.

Hypertensive disorders of pregnancy (HDP), including gestational hypertension $(\mathrm{GH})$ and preeclampsia, are among the most common complications of pregnancy. Previous studies have found associations between maternal HDP and the hematological profile of newborns, preterm birth, low birth weight, and slower growth patterns in early infancy ${ }^{(13)}$.

Kazmi et al. ${ }^{(13)}$ identified associations between both maternal HDP and preeclampsia and DNA methylation at several loci across the genome in cord blood.

HDP and a higher maternal BP across pregnancy are associated with small for gestational age, low birth weight, and a shorter gestation ${ }^{(\mathbf{1 4})}$. We did not adjust our main analyses for gestational age or birth weight as these could not plausibly influence HDP (and so could not confound the association) but may be on a causal path between HDP and its treatment (including early delivery) and cord blood DNA methylation ${ }^{(\mathbf{1 3})}$.

Çağlar et al. ${ }^{(9)}$ found CO, stroke volume, but not significantly, lower and SVR was significantly higher in the PE group than the control group.

Previous studies on cardiac changes in PE mainly focused on left ventricular (LV) systolic function; however, the results were contradictory. Furthermore, even less data exist about changes in myocardial and diastolic function in PE, which were shown to precede impairment of contractile dysfunction in the evaluation of most cardiac diseases ${ }^{(\mathbf{1 5})}$.

Regarding PIU distribution in the patients' group (preeclampsia), it was $1+$ in $12(30 \%), 2+$ in 11 $(27.5 \%)$ and $3+$ in $17(42.5 \%)$. The echographic parameters of the left ventricle, the mean LVEDD, LVESD, FS\%, and EF\%, showed non-significant difference between patients and control groups as.

Çağlar et al. ${ }^{(9)}$ found EF\% was slightly, but not significantly, lower and SVR was significantly higher in the PE group than the control group. They added that 
myocardial performance index (MPI) is a less loadand heart rate-dependent parameter that provides information about both systolic and diastolic function.

LV-EF\% is usually within normal limits during $\mathrm{PE}$, as in our study. However, Melchiorre et al. (16) demonstrated impaired LV longitudinal, circumferential and radial systolic strain in patients with PE. They concluded that, although subclinical, there was a reduction in systolic function.

Heart rate, rhythm, contractility, and overload affect right ventricular performance ${ }^{(\mathbf{1 7})}$. To date, there have been a limited number of echocardiographic studies evaluating the right-sided cardiovascular system in patients with PE. Uterine pressure on the inferior vena cava, and hemodynamic alterations and echogenicity problems due to increased breast tissue during pregnancy, are all factors that make functional assessment of the right heart challenging on conventional 2D echocardiography ${ }^{(\mathbf{1 8})}$.

However, there are some publications in the literature indicating that E/E0 has limited clinical value. For example, Previtali et al. ${ }^{(19)}$ assessed the predictive value of the mitral E/E0 ratio for left ventricular diastolic pressure in patients without heart failure (HF). They demonstrated that E/E0 was highly dependent on EF and LV dilatation such that its predictive value in patients without heart failure was questionable. EF was also within the normal range, and LV was not dilated, in our study.

Little is known about acute and long-term effects of $\mathrm{PE}$ on right ventricular (RV) structure and function. Recent advances in echocardiographic methodology include Doppler tissue imaging echocardiography, which has been proven to be particularly useful in the evaluation of ventricular function ${ }^{(20)}$.

The echographic parameters of the right ventricle showed a statistically significant difference between patients and control groups as regard the mean TAPSE, ESPAP, FAC\%, RIMP, and TDI. These results indicated that there is right ventricular dysfunction in the preeclamptic patients compared to controls.

Similar to our findings, Dennis and Castro ${ }^{(21)}$ evaluated cardiac function indices using transthoracic echocardiography in women treated for severe PE, and demonstrated that the left ventricle was not dilated and end-diastolic diameters were within healthy reference ranges. They also showed reduced diastolic function. We also demonstrated significant differences in diastolic parameters between groups; however, the results were within healthy reference ranges. The difference between the two studies concerned the severity of PE.

Thus, we used multiple echocardiographic parameters. FAC and TAPSE are two reliable parameters for the evaluation of RV global systolic function. However, they are load-dependent indices, which limit their use in the volume-overloaded state of pregnancy ${ }^{(18)}$. Thus, we also assessed less loaddependent indices. Although the results were within normal ranges, all of the echocardiographic parameters for RV systolic functions were lower in patients with PE than healthy pregnant women.

As findings Çağlar et al. (9) suggest RV subclinical structural and functional changes in patients with PE. Impairment of the right side of the cardiovascular system may be due to increased pulmonary resistance due to insufficient left ventricular compliance, secondary to increased left ventricular diastolic filling pressures (16). This hypothesis was partially supported by our findings that pointed to increased mean pulmonary artery pressure in the PE group versus the control group, although the results were within normal ranges, the same was documented by Çağlar et al. ${ }^{(9)}$. Similarly, Melchiorre et al. (16) also demonstrated RV dysfunction in preeclamptic patients with LV dysfunction and mentioned that this was associated with increased pulmonary vascular resistance secondary to increased LV filling pressure.

Alterations in RV structure and volume may contribute to RV dysfunction. Right ventricular basal diameter (RV-Bd) measurement is known to be correlated with RV volume and to have a tendency to increase under chronic pressure and volume ${ }^{(\mathbf{1 8})}$. RV free wall thickness (RV-Wth) is a useful technique to evaluate RV hypertrophy. Increased RV systolic pressure during PE may cause RV hypertrophy and right atrial enlargement. RV-Bd and RV-Wth measurements were significantly higher in patients with PE than controls ${ }^{(9)}$.

$\mathrm{RV}$ diastolic function begins to deteriorate before RV geometrical and systolic impairment. PDI measurements showed reduced $\mathrm{E}$ wave velocity and E/A ratio and prolonged DT in patients with $\mathrm{PE}$ versus controls ${ }^{(9)}$. They demonstrate early deterioration in diastolic filling. As PDI is a load-dependent index that is affected by heart rate and inspiration, also they demonstrated impaired RV diastolic function during PE. The E/e0 ratio is correlated with invasively measured mean RA pressure and reflects RV filling pressures. The E/e0 ratio was significantly higher in the PE group than the control group in their study. However, this finding alone is insufficient for predicting increased right atrial pressure and stating a clinical outcome.

Two-dimensional (2D) speckle-tracking echocardiography (STE) indices are able to reflect the morphological state of the heart, further our understanding of myocardial deformation, and are even sensitive in detecting subtle myocardial damage (22).

On comparison of Global Longitudinal Strain (GLS (2d-speckle)) between patients and control 
groups, we found highly significant difference between the 2 groups.

However, in contrary to our study, Cong et al. ${ }^{\text {(23) }}$ found that there was no significant change in GLS and the value of GCS was higher in LP vs. EP. PE is not just hypertension alone, but a complex complication of pregnancy. Moreover, many different biochemical markers, and genetic and environmental risk factors have been found to be associated with EP and LP, which could result in the inconsistency ${ }^{(24)}$.

Interestingly, Cong et al. ${ }^{(23)}$ compared PE with normal pregnant women, there were no significant changes in value of global radial strain (GRS) in PE group. They attributed this to one possible reason; is the calculation of GRS depends on both endocardial and epicardial speckle tracking qualities, whereas GLS, GCS and GRS are estimated only by endocardial data. Thus, GRS measurements might be less accurate and show greater variability. Another reason may be that radial systolic function changes later than longitudinal systolic function in cardiac ischemia ${ }^{(25)}$. In addition, Cong et al. (23) demonstrated that myocardial dysfunction precedes chamber dysfunction and therefore the measurements of $2 \mathrm{D}$ or $3 \mathrm{D}$-derived strain are able to detect early signs of cardiac abnormality in this hypertensive disorder complicating pregnancy.

Comparison between before labor and 6 weeks after labor of the left ventricle of the preeclamptic patients showed that LVEDD, LVESD, FS\%, and FF\% had a statistically highly significant difference.

Al-Nashi et al. ${ }^{(20)}$ found no evidence of cardiac remodeling or functional LV or RV impairment, and no signs of alterations in aortic stiffness or ventriculararterial coupling in women with a history of PE. Furthermore, 11 years postpartum women with a history of early and severe PE did not differ with regard to cardiac structure and function from the remaining women in the PE group.

The present study supported by the previous investigations assessing persistence of preeclampsiainduced LV remodeling by the size of the cohort ( $\mathrm{n}=$ 131 ), the length of follow-up (9 to 16 years) and the adjustment of outcomes for cardiovascular risk factors such as age, smoking, blood pressure, BMI and educational level ${ }^{(26)}$.

LV dilatation and hypertrophy, and impaired systolic and diastolic function are common findings associated with acute PE, and these findings were shown to persist 3 years after PE ${ }^{(27)}$. However, few studies have assessed LV mass and geometry by echocardiography at long-term follow-up after PE. We found similar left atrial and ventricular dimensions and LV mass in the two study groups 11 years after the index pregnancy ${ }^{(20)}$. This supports findings in women 40 years after hypertensive pregnancies, where LV mass index and relative wall thickness were the same as in women with a normal pregnancy. Of note, only two of three examined women with a hypertensive pregnancy in that study had PE. Thus, LV structural changes during PE seem to be transient and do not persist 11 years later, and may not be a risk factor per se for future cardiovascular disease ${ }^{(28)}$.

We observed normal LV systolic and diastolic function and no differences between the PE group and the control group. Our findings are novel in that we also included new sensitive echocardiographic techniques (two-dimensional speckle-tracking echocardiography strain analysis) as Al-Nashi $\boldsymbol{e t}$ al. ${ }^{(20)}$ who used twodimensional speckle-tracking echocardiography strain analysis and Doppler tissue imaging and circulating biomarkers (NT-pro-BNP) to specifically evaluate LV systolic and diastolic function and that their patients were examined long (11 years) after the index pregnancy.

In contrast, elevated myocardial performance index values, indicating impairment of systolic and diastolic function in asymptomatic women with a history of PE 13-17 years after the index pregnancy were reported by Strobl $\boldsymbol{e t}$ al. ${ }^{(29)}$. The authors only reported on myocardial performance index. This is a global index calculated as a ratio of systolic and diastolic time intervals, which does not require information on LV geometry, volume-based systolic LV function, or myocardial LV deformation. This makes a comparison to our results difficult.

LV end-systolic elastance is an important marker of LV performance. LV end-systolic elastance is impaired during PE and in the early postpartum period, and cardiac performance may not be fully restored after 3 years ${ }^{\left({ }^{17)} \text {. }\right.}$

Comparison between before labor and 6 weeks after labor of the right ventricle of the preeclamptic patients showed that TAPSE, ESPAP, FAC, RIMP, TDI (S'), and GLS (2D speckle) had highly significant difference.

Regarding the correlation coefficient ( $r$ ) between TAPSE and GLS (2D speckle) of PE patients before labor and 6 weeks after labor; they showed a statistically highly significant coefficients.

Vaddamani et al. ${ }^{(30)}$ studied women with early onset preeclampsia (EOPE), <34 weeks gestation, and late onset preeclampsia (LOPE), >34 weeks gestation, by $2 \mathrm{D}$-speckle echocardiography and found that EOPE had higher total vascular resistance (TVR) index compared to those with LOPE demonstrating greater rise in stroke volume, cardiac output and cardiac workload normalized for body surface area in our study. This is similar to the findings in the study by Valensise et al. ${ }^{(27)}$ who noticed that these two groups to differ in the hemodynamic indices at 24 weeks' gestation, much before manifestation of preeclampsia, and these changes persisted even one year postpartum. These hemodynamic differences lead them to suggest the varied origins of both forms of preeclampsia; 
EOPE being the evolution of an extreme cardiovascular disorder secondary to defective trophoblastic invasion in placental development and LOPE probably linked to the maternal constitutional factors such as body mass index.

Also, Orabona et al. ${ }^{(7)}$ findings was as follows: (1) most EOPE cases, together with a smaller proportion of LOPE cases, showed subclinical impairment of systolic biventricular function, as evidenced by reductions in LV 2D strain (circumferential, radial and longitudinal) and RV 2D strain, and impairment of LV torsional mechanics, when compared with matched controls; (2) atrial function was preserved in the entire study cohort, although the left atrial longitudinal peak at the end of LV systole (LAs) strain was impaired in the EOPE group; (3) VAC was maintained within normal range, albeit its components were altered in some cases with previous EOPE; (4) STE and VAC parameters (except RV 2D strain) were associated independently with GA at diagnosis of $\mathrm{PE}$, after correcting for possible confounders (i.e. SBP/DBP, mean UtA- PI and birth weight $<10^{\text {th }}$ percentile).

Although it is not still understood whether PE causes permanent $\mathrm{CV}$ damage or whether preeclamptic women have pre- existing alterations, the development of PE may lead to identification of women at high risk before other $\mathrm{CV}$ risk factors become apparent. Previous reports on cardiac performance in previously preeclamptic women reported a permanent subclinical LV dysfunction, namely, asymptomatic heart failure (27). The early detection of functional alterations is challenging using traditional ejection phase indices (e.g. LVEF), which depend on loading condition, heart rate and LV geometry ${ }^{(7)}$.

\section{CONCLUSIONS}

Two-dimensional speckle echocardiography proved to be acceptable, and applicable for assessing right-sided heart function in patients with preeclampsia. Using this image modality demonstrate significant differences in right ventricular measurements to overcome further morbidity and mortality of those patients.

\section{REFERENCES}

1. Hernandez-Diaz S, Toh S, Cnattingius $S$ (2009): Risk of pre-eclampsia in first and subsequent pregnancies: prospective cohort study. BMJ., 338:b2255.

2. American College of Obstetricians and Gynecologists, Task force Hypertension in Pregnancy (2013): Hypertension in pregnancy. Report of the American College of Obstetricians and Gynecologists' Task Force on Hypertension in Pregnancy. Obstet Gynecol., 122(5):112231.

3. Paauw ND and Lely AT (2018): Cardiovascular Sequels During and After Preeclampsia. Adv Exp Med Biol., 1065:455-470.
4. Kyung Choi S, Chul Shin J, Gyu Park Y, Yang Park I, Young Kwon J, Sun Ko H, Hee Kim Y (2017): The efficacy of peripartum transthoracic echocardiography in women with preeclampsia. Pregnancy Hypertens., 10:187-191.

5. Guirguis GF, Aziz MM, Boccia Liang C, Williams SF, Apuzzio JJ, Bilinski R, Mornan AJ, Shah LP (2015): Is preeclampsia an independent predictor of diastolic dysfunction? A retrospective cohort study, Pregnancy Hypertens., 5 (4) 359-361.

6. Melchiorre K, Sutherland GR, Baltabaeva A, Liberati M, Thilaganathan B (2011): Maternal cardiac dysfunction and remodeling in women with preeclampsia at term. Hypertension, 57(1): 85.

7. Orabona R, Vizzardi E, Sciatti E, Bonadei I, Valcamonico A, Metra M, Frusca T (2017): Insights into cardiac alterations after pre-eclampsia: an echocardiographic study. Ultrasound Obstet Gynecol., 49(1): 124-133.

8. Longobardo L, Suma V, Jain R, Carerj S, Zito C, Zwicke DL, Khandheria BK (2017): Role of TwoDimensional Speckle-Tracking Echocardiography Strain in the Assessment of Right Ventricular Systolic Function and Comparison with Conventional Parameters. J Am Soc Echocardiogr., 30(10): 937-946.e6.

9. Çağlar FN, Ozde C, Bostancı E, Çağlar İM, Çiftçi S, Unğan İ, Demir B, Karakaya O (2016): Assessment of right heart function in preeclampsia by echocardiography. Pregnancy Hypertens., 6(2): 89-94.

10. Lang $\mathrm{R}$, Badano $\mathrm{L}$, Mor-Avi $\mathrm{V}$ et al. (2015) 'Recommendations for cardiac chamber quantification by echocardiography in adults: An update from the American society of echocardiography and the European association of cardiovascular imaging', European Heart Journal Cardiovascular Imaging. Elsevier Inc, 16(3):233-271.

11. Rudski LG, Lai WW, Afilalo J, Hua L, Handschumacher MD, Chandrasekaran K, Solomon SD, Louie EK, Schiller NB (2010): Guidelines for the echocardiographic assessment of the right heart in adults: a report from the American Society of Echocardiography: endorsed by the European Association of Echocardiography, a registered branch of the European Society of Cardiology, and the Canadian Society of Echocardiography. Journal of the American Society of Echocardiography, 23(7):685-713.

12. Abalos E, Cuesta C, Carroli G, Qureshi Z, Widmer M, Vogel JP, Souza JP (2014): Preeclampsia, eclampsia and adverse maternal and perinatal outcomes: a secondary analysis of the World Health Organization Multicountry Survey on Maternal and Newborn Health, BJOG., $121: 1$ 14-24.

13. Kazmi N, Sharp GC, Reese SE, Vehmeijer FO, Lahti J, Page CM et al. (2019): Hypertensive Disorders of Pregnancy and DNA Methylation in Newborns. doi: 10.1161/hypertensionaha.119.12634.

14. Macdonald-Wallis C, Tilling K, Fraser A, Nelson SM, Lawlor DA (2014): Associations of blood pressure change in pregnancy with fetal growth and gestational age at delivery: findings from a prospective cohort. Hypertension, 64:36-44.

15. Cong J, Yang $X$, Zhang $N$, Shen J, Fan T, Zhang $Z$ (2015a): Quantitative analysis of left atrial volume and function during normotensive and preeclamptic 
pregnancy: a realtime three-dimensional echocardiography study, Int. J. Cardiovasc., 31 (4): 805812.

16. Melchiorre K, Sutherland GR, Watt-Coote I, Liberati M, Thilaganathan B (2012): Severe myocardial impairment and chamber dysfunction in preterm preeclampsia, Hypertens. Pregnancy, 31 (4): 454-471.

17. Estensen ME, Remme EW, Grindheim G, Smiseth OA, Segers P, Henriksen T, Aakhus S (2013): Increased arterial stiffness in pre-eclamptic pregnancy at term and early and late postpartum: a combined echocardiographic and tonometric study, Am. J. Hypertens., 26(4): 549-556.

18. Vogel M, Derrick G, White PA, Cullen S, Aichner H, Deanfield J, Redington AN (2004): Systemic ventricular function in patients with transposition of the great arteries after atrial repair. A tissue Doppler and conductance catheter study, J. Am. Coll. Cardiol., 43: 100-106.

19. Previtali M, Chieffo E, Ferrario M, Klersy C (2012): Is mitral E/E0 ratio a reliable predictor of left ventricular diastolic pressures in patients without heart failure?, Eur Heart J. Cardiovasc. Imaging, 13 (7): 588-595.

20. Al-Nashi M, Eriksson MJ, Östlund E, Bremme K, Kahan T (2016): Cardiac structure and function, and ventricular-arterial interaction 11 years following a pregnancy with preeclampsia. J Am Soc Hypertens., 10(4):297-306.

21. Dennis AT, Castro JM (2014): Transthoracic echocardiography in women with treated severe preeclampsia, Anaesthesia, 69 (5): 436-44.

22. Ammar KA, Paterick TE, Khandheria BK, Jan MF, Kramer C, Umland MM, Tercius AJ, Baratta L, Tajik AJ (2012): Myocardial mechanics: understanding and applying three-dimensional speckle tracking echocardiography in clinical practice. Echocardiography, 29:861-872.

23. Cong J, Fan T, Yang X, Shen J, Cheng G, Zhang Z (2015b): Maternal cardiac remodeling and dysfunction in preeclampsia: a three-dimensional speckle-tracking echocardiography study. Int $\mathrm{J}$ Cardiovasc Imaging, 31(7):1361-8.

24. Raymond D and Peterson E (2011): A critical review of early-onset and late-onset preeclampsia. Obstet Gynecol Surv., 66 (8):497-506.

25. Bolognesi R, Tsialtas D, Barilli AL, Manca C, Zeppellini R, Javernaro A, Cucchini F (2001): Detection of early abnormalities of left ventricular function by hemodynamic, echo-tissue Doppler imaging, and mitral Doppler flow techniques in patients with coronary artery disease and normal ejection fraction. J Am Soc Echocardiogr., 14:764-772.

26. Caballero L, Kou S, Dulgheru R, Gonjilashvili N, Athanassopoulos GD, Barone D et al. (2015): Echocardiographic reference ranges for normal cardiac Doppler data: results from the NORRE Study. Eur Heart J Cardiovasc Imaging, 16(9):1031-41.

27. Valensise H, Vasapollo B, Gagliardi G, Novelli GP (2008): Early and late preeclampsia: two different maternal hemodynamic states in the latent phase of the disease. Hypertension, 52:873-80.

28. Collen AC, Hellgren M, Gustafsson H, Johansson MC, Manhem K (2013): Cardiovascular and metabolic characteristics 40 years after hypertensive pregnancies: a longterm follow-up study of mothers. J Hypertens., 31: 758-65.

29. Strobl I, Windbichler G, Strasak A, Weiskop F, Schwendinger V, Schweigmann U, Ramoni A et al. (2011): Left ventricular function many years after recovery from pre-eclampsia. BJOG., 118:76-83.

30. Vaddamani S, Keepanasseril A, Pillai AA, Kumar B (2017): Maternal cardiovascular dysfunction in women with early onset preeclampsia and late onset preeclampsia: A cross-sectional study. Pregnancy Hypertens., 10:247-250. 